\title{
Campanulaceae no Parque Nacional do Itatiaia, Brasil
}

\author{
Campanulaceae from the Itatiaia National Park, Brazil
}

\author{
Isis de Mello Rollim ${ }^{1,2}$ \& Marcelo Trovó ${ }^{1}$
}

\begin{abstract}
Resumo
O presente manuscrito apresenta o tratamento florístico de Campanulaceae no Parque Nacional do Itatiaia. A família está representada na área por três gêneros, Lobelia com duas espécies: L. camporum e L. fistulosa, Siphocampylus, com quatro espécies: S. duploserratus, S. longepedunculatus, S. umbellatus e S. westinianus e Wahlenbergia, com uma espécie: $W$. linarioides. As espécies foram encontradas majoritariamente na parte alta do parque, geralmente associadas a afloramentos rochosos dos campos de altitude, com vegetação graminoide ao redor. Somente S. longepedunculatus foi coletado em sub-bosque de floresta ombrófila, em local úmido. São fornecidas descrições, chave de identificação, além de comentários sobre distribuição geográfica, hábitat e variação morfológica das espécies.
\end{abstract}

Palavras-chave: Flora, Lobelia, Siphocampylus, taxonomia, Wahlenbergia.

\begin{abstract}
This manuscript presents the floristic treatment of Campanulaceae in the Itatiaia National Park. The family is represented in the area by three genera, Lobelia with two species: L. camporum and L. fistulosa, Siphocampylus, with four species: S. duploserratus, S. longepedunculatus, S. umbellatus e $S$. westinianus, and Wahlenbergia, with one species: $W$. linarioides. The species were mostly found in the upper part of the park, usually in the rocky outcrops of the high fields, surrounded by graminoid vegetation. Only $S$. longepedunculatus was collected in rain forest understory, in moist places. Descriptions, an identification key, as well as comments on geographic distribution, habitat and morphological variation of species are provided.
\end{abstract}

Key words: Flora, Lobelia, Siphocampylus, taxonomy, Wahlenbergia.

\section{Introdução}

Campanulaceae possui distribuição cosmopolita, não ocorrendo apenas em áreas desérticas, Antártida e norte da Groenlândia. Ocupa os mais variados hábitats, principalmente orlas ou interior de matas de galeria e matas ciliares, campos rupestres e brejos (Angely 1985). É uma família bastante diversa, abrangendo três subfamílias, cerca de 84 gêneros e aproximadamente 2.400 espécies. No Brasil são listados seis gêneros e 56 espécies, destas 39 são endêmicas do país (BFG 2015).

Cronquist (1981) cita a formação de látex, presença de estilete sem indúsio e com tricomas coletores, androceu isostêmone com cinco estames e anteras introrsas, como características que delimitam a família. As folhas são simples, podendo ser inteiras ou serreadas, com nervação peninérvea, quase sempre se dispõem alternadamente. As inflorescências podem ser terminais ou axilares, com flores vistosas e caracterizadas também pela protandria. Diversas espécies de Lobelia produzem alcaloides com possibilidades farmacológicas sendo, portanto de considerável interesse econômico (Braga 1956; Bório 1968; Krochmal et al. 1970).

O conhecimento acerca das Campanulaceae brasileiras ainda é escasso e restrito a algumas listagens. Além da revisão para a Flora Brasiliensis realizada por Kanitz (1878), só há conhecimento sobre a família em algumas regiões de Minas Gerais e nas floras de Santa Catarina e São Paulo. Montlavo (1977) estudou as Campanulaceae encontradas no município do Rio de Janeiro e

\footnotetext{
${ }^{1}$ Universidade Federal do Rio de Janeiro, Lab. Integrado de Sistemática Vegetal, Depto. Botânica, Inst. Biologia, CCS, B1. A1, Cidade Universitária, 21941-590, Rio de Janeiro, RJ, Brasil.

${ }^{2}$ Autor para correspondência: isisrollim@gmail.com
} 
Angely (1985) apresentou vários aspectos históricos e geográficos do gênero Lobelia e da família. Entretanto, pouco se conhece acerca da diversidade taxonômica, morfológica e distribuição geográfica das Campanulaceae no estado do Rio de Janeiro e em especial no Parque Nacional do Itatiaia.

O Parque Nacional do Itatiaia é o primeiro Parque Nacional do Brasil e sua fundação ocorreu na década de 1930. Possui relevo bastante acidentado e uma grande diversidade de hábitat e espécies. É uma das áreas principais para conservação da Serra da Mantiqueira, uma vez que abriga inúmeras espécies endêmicas e está entre três grandes metrópoles, Belo Horizonte, Rio de Janeiro e São Paulo (Ibama 1994). Deste modo, o presente trabalho teve por objetivo realizar o tratamento florístico das espécies de Campanulaceae ocorrentes no Parque Nacional do Itatiaia, embasando futuras estratégias de conservação e o monitoramento da Unidade de Conservação.

\section{Material e Métodos}

Para este estudo foram consultadas as coleções dos herbários GUA, HB, SPF, SP, R, RB, RFA. Expedições a campo ao Parque Nacional do Itatiaia foram realizadas entre 2013 e 2015, durante os meses de verão e inverno. Foram coletados espécimes férteis, os quais foram herborizados seguindo técnicas usuais em taxonomia e posteriormente depositados no herbário da Universidade Federal do Rio de Janeiro (RFA), com duplicatas enviadas para outras instituições. As descrições foram realizadas com auxílio de microscópio estereoscópico e baseadas na morfologia externa dos materiais examinados. Os espécimes foram identificados com base na bibliografia específica da família. As espécies são apresentadas em ordem alfabética, sendo fornecidas descrições, chave de identificação, comentários e informações sobre distribuição geográfica e hábitat.

\section{Resultados e Discussão}

Neste estudo foram registradas sete espécies de Campanulaceae distribuídas em três gêneros, Lobelia com duas espécies: L. camporum e $L$. fistulosa, Siphocampylus, com quatro espécies: $S$. duploserratus, S. longepedunculatus, $S$. umbellatus e $S$. westinianus e Wahlenbergia, com uma espécie: $W$. linarioides. A maioria das espécies tem ampla distribuição, encontradas em regiões serranas, campos de altitude, brejo, restingas e menos frequentemente em cerrados. Os exemplares coletados foram encontrados majoritariamente nos campos de altitude, geralmente em beira de trilhas ou afloramentos rochosos com vegetação graminóide abundante ao redor. Somente Siphocampylus longepedunculatus foi encontrada na beira de trilhas em sub-bosque de floresta ombrófila, em locais onde a umidade é maior.

\section{Chave de identificação das espécies de Campanulaceae no Parque Nacional do Itatiaia}

1. Flores actinomorfas em inflorescência paniculada, corola campanulada, filetes e anteras livres.

1'. Flores zigomorfas, solitárias, em inflorescência racemosa ou corimbiforme, corola tubulosa, filetes e anteras unidas

2. Tubo da corola longitudinalmente fendido, violáceo ou violeta-rosado ............................................ 3

2'. Tubo da corola inteiro, amarelado, alaranjado, vermelho ou esverdeado .......................................... 4

3. Ervas com caule maciço até 1 metro de comprimento, corola violácea .....

1. Lobelia camporum

3'. Ervas com caule fistuloso podendo alcançar até 3 metros de comprimento, corola violetarosada

2. Lobelia fistulosa

4. Tubo da corola curto, menor que os lobos, hipanto achatado globoso

5. Siphocampylus umbellatus

4'. Tubo da corola longo, cerca de 2 a 3 vezes maior que os lobos, hipanto obcônico ..........5

5. Folhas alternas, base cordada.......................... Siphocampylus longepedunculatus

5'. Folhas verticiladas, base arredondada ou aguda .

6. Três folhas por verticilo, margem denteado-denticulada com dentes desiguais, lobos da corola com base amarelada e ápice verde.

3. Siphocampylus duploserratus

6'. Três ou quatro folhas por verticilo, margem denteado-denticulada com dentes iguais, lobos da corola amarelos ou verdes. 6. Siphocampylus westinianus 


\section{Lobelia camporum Pohl}

Fig. 1a,b

Ervas com caule até $1 \mathrm{~m}$ de compr., maciço, latescente, glabro a pubescente. Folhas sésseis, espatulada ou oblonga; lâmina $1,5-7 \times 0,2-0,7$ $\mathrm{cm}$, glabra, ápice acuminado, margem denteada, base cuneada, nervuras secundárias até 9 pares. Racemo com bráctea $0,4-1,8 \times 0,1-0,5 \mathrm{~cm}$, séssil, lanceolada, glabra a pubescente, ápice agudo, margem denteada. Flores zigomorfas; pedicelo ca. $3 \mathrm{~mm}$ compr., glabro a pubescente; hipanto 2-4 × 5-10 mm, obcônico; lobos do cálice 4-6 $\times 1-2 \mathrm{~mm}$, ápice agudo, margem denteada; corola $0,7-1,7 \mathrm{~cm}$ compr., tubulosa, pubescente, violácea; tubo dos filetes 3-6 mm compr., glabro, base ciliada; tubo de anteras $2-4 \mathrm{~mm}$ compr., as menores com ápice piloso.

Comentários: Ocorre nas regiões de altitudes superiores a $1.000 \mathrm{~m}$. Muito frequente nos afloramentos rochosos dos campos de altitude do Sudeste, Sul e Centro-Oeste do Brasil (BFG 2015). Coletada com flores durante o ano todo, com maior concentração nos meses mais quentes. Facilmente reconhecida pela corola que lembra o formato de asas, característica que justifica o nome popular 'voadora-do-brejo'.

Material examinado: III.1894, fl., E. Ule 208 (R); 23.VII.1901, fl., Hermendorff 549 (R); 21.V.1902, fl., P. Dusen 60 (R); 2.III.1921, fl., P. Campos Porto 1034 (RB); IV.1921, fl., P. Occhioni (RB 16468); 26.III.1943, fl., E. Pereira 39B (RB); 6.III.1962, fl., E. Pereira 7049 (HB); 13.IV.1963, fl., E. Pereira 7577 (HB); 30.XII.1966, fl., H. Strang 761 (HB); 6.II.1969, fl., D. Sucre 4658 (RB); 15.III.1975, fl., A.M. Camerik (RB 530600); 2.V.1985, fl., G. Martinelli 10834 (RB); 15.II.1995, f1., J.M.A. Braga 2056 (RB); 9.IV.1995, fl., J.M.A. Braga 2318 (RB); 26.V.2013, fl., I.M. Rollim 06 (RFA); 26.V.2013, fl., I.M. Rollim 07 (RFA); 26.V.2013, fl., I.M. Rollim 08 (RFA); 6.IV.2014, fl., I.M. Rollim 23 (RFA); 6.IV.2014, fl., I.M. Rollim 25 (RFA).

\section{Lobelia fistulosa Vell.}

Fig. $1 \mathrm{c}, \mathrm{d}$

Ervas com caule de 1-3 m de compr., fistuloso, latescente, glabro a pubescente. Folhas sésseis, oblonga; lâmina 8-50 × 2,5-6 cm, glabra, ápice agudo, margem denteada ou ciliada, base decurrente, nervuras secundárias 9-24 pares. Racemo com bráctea 2,5-4 × 1-2,5 cm, séssil, lanceolada, glabra, ápice acuminado a agudo, margem ciliada. Flores zigomorfas; pedicelo 6-10 cm compr., hirsuto; hipanto 6-12 × 3-4 mm, campanulado; lobos do cálice 1-2,5 × 0,2-0,4 $\mathrm{cm}$, ápice acuminado, margem íntegra; corola 3-5 cm compr., tubulosa, hirsuta, violeta-rosada; tubo dos filetes 3-4 cm compr., pubérulo; tubo de anteras $8-18 \mathrm{~mm}$ compr., as menores com ápice piloso.

Comentários: Ocorre geralmente em áreas abertas, bordas de floresta ou clareiras. Está distribuída majoritariamente nos campos de altitude e campos rupestres do Sudeste do Brasil (BFG 2015). Encontrada com flores e frutos predominantemente nos primeiros meses do ano. Distingui-se facilmente de L. camporum por ser uma erva robusta de corola violeta-rosada. Embora a espécie ocorra com frequência em diversas serras nas adjacências, não foi coletada no parque nos últimos 70 anos.

Material examinado: I.1939, fl., L. Laustiaki 296 (RB); 28.I.1943, fl., J. Sampaio (RB 53160).

\section{Siphocampylus duploserratus Pohl.}

Fig. 1e,f

Ervas com 0,3-1 m de compr., pouco ramificadas, latescentes; ramos glabros. Folhas verticiladas, 3 folhas por verticilo; pecíolo 1,5-3 cm compr.; lâmina 3,5-8 × 1,6-4,5 cm, oval a oblonga, ápice subacuminado, margem denteadodenticulada com muitos dentes desiguais, base arrendondada ou aguda, membranácea, face adaxial com tricomas esparsos, face abaxial pilosa. Flores zigomorfas, isoladas, axilares; pedicelo 3-6 cm compr., pubérulo, 2-bracteolado ou não; hipanto 4-8 × 4-6 mm, obcônico; lobos do cálice $0,3-0,8 \mathrm{~cm}$ compr., subulados, margem denticulada; corola 4-5,6 cm compr., tubulosa, subereta, vermelha, lobos disjuntos a partir de $3 / 4$ da base, amarelos ou verdes; tubo de filetes glabro, tubo de anteras ca. $6 \mathrm{~mm}$ compr., cinza azulado.

Comentários: Espécie de difícil delimitação, uma vez que suas flores se assemelham com $S$. westinianus. Pode ser reconhecida quanto à disposição das folhas que são verticiladas na maior parte da planta, mas na parte inferior dos ramos podem apresentar-se alternas. A margem das folhas com dentes desiguais também é útil na distinção da espécie. Wimmer (1953) propõe duas variedades, sendo que o material proveniente do Itatiaia acomoda-se bem em $S$. duploserratus var. duploserratus. Pode ser encontrada com frequência nos campos de altitude do Sudeste do Brasil (BFG 2015). Há uma maior concentração de indivíduos férteis entre os meses de dezembro a março.

Material examinado: 21.I.2003, fl., A. Quinet 755 (RB); 05.III.2013, fl., L.N. Gonçalves 2 (RB); 

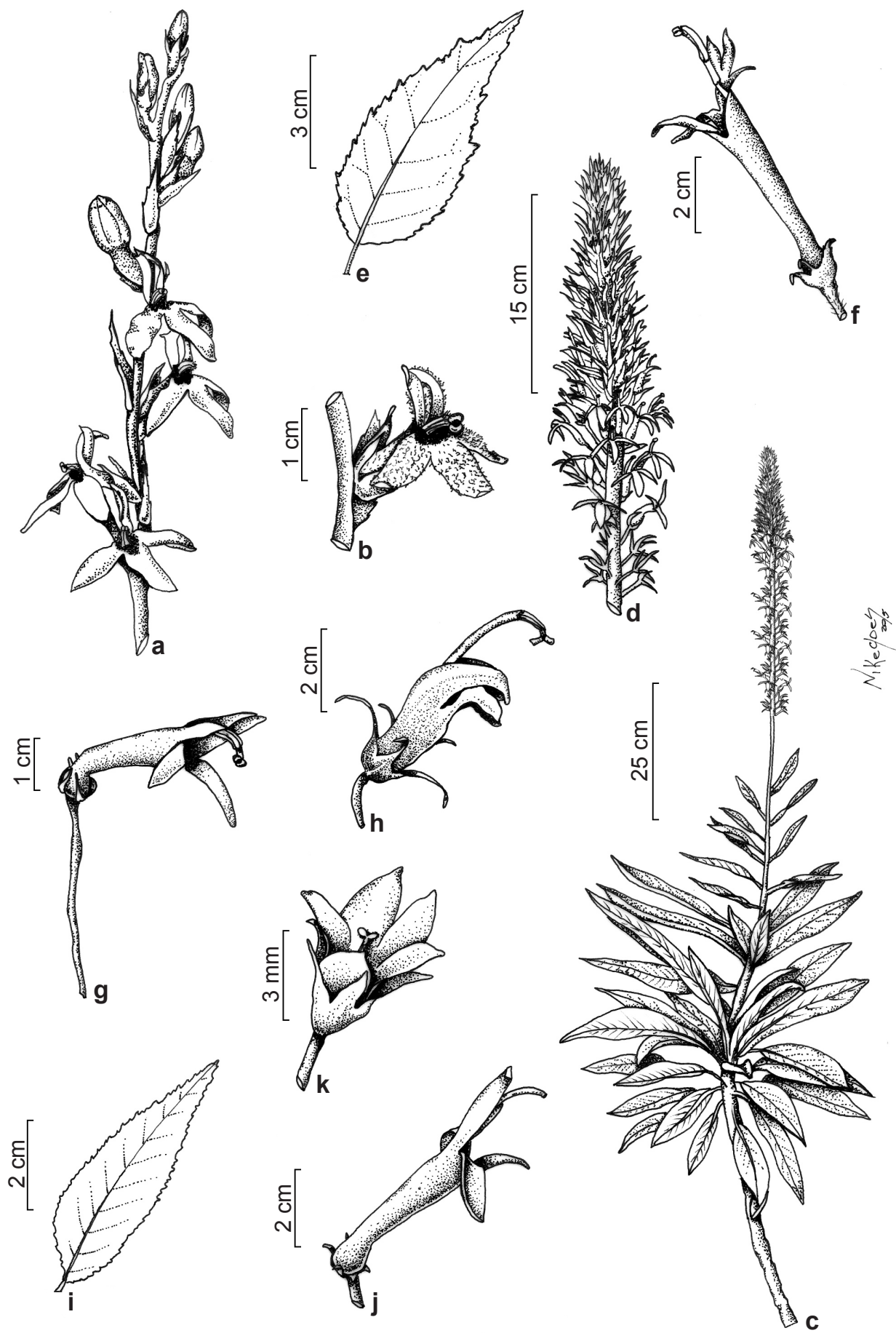

Figura 1 - Espécies de Campanulaceae do Parque Nacional do Itatiaia, Rio de Janeiro (Brasil) - a. hábito de Lobelia camporum; b. detalhe da flor de Lobelia camporum; c. hábito de Lobelia fistulosa; d. detalhe da inflorescência de Lobelia fistulosa; e. detalhe da folha de Siphocampylus duploserratus; f. detalhe da flor de Siphocampylus duploserratus; g. detalhe da flor de Siphocampylus longepedunculatus; h. detalhe da flor de Siphocampylus umbellatus; i. detalhe da folha de Siphocampylus westinianus; $\mathrm{j}$. detalhe da flor de Siphocampylus westinianus; $\mathrm{k}$. detalhe da flor de Wahlenbergia linarioides. Figure 1 - Campanulaceae species from the Itatiaia National Park, Rio de Janeiro (Brazil) - a. habit of Lobelia camporum; b. flower detail of Lobelia camporum; c. habit of Lobelia fistulosa; $\mathrm{d}$. inflorescence detail of Lobelia fistulosa; e. leaf detail of Siphocampylus duploserratus; f. flower detail of Siphocampylus duploserratus; g. flower detail of Siphocampylus longepedunculatus; h. flower detail of Siphocampylus umbellatus; i. leaf detail of Siphocampylus westinianus; $\mathrm{j}$. flower detail of Siphocampylus westinianus; $\mathrm{k}$. flower detail of Wahlenbergia linarioides. 
26.V.2013, fl., I.M. Rollim 10 (RFA), 06.IV.2014, fl., I.M. Rollim 22 (RFA); 06.IV.2014, fl., I.M. Rollim 26 (RFA); 05.V.2015, fl., I.M. Rollim 30 (RFA).

\section{Siphocampylus longepedunculatus Pohl}

Fig. $1 \mathrm{~g}$

Ervas com 0,6-1,2 m de compr., escandentes, latescentes; ramos glabros. Folhas alternas; pecíolo $0,6-1,8 \mathrm{~cm}$ compr.; lâmina 3-10 × 1,5-5 $\mathrm{cm}$, oval a alongado-triangular, ápice acuminado, margem denteado-denticulada, base cordada, membranácea, face adaxial glabra, face abaxial com tricomas nas nervuras. Flores zigomorfas, isoladas, axilares; pedicelo 3,2-12 cm compr., glabro, não bracteolado; hipanto 5-6 × 4-6 m, obcônico; lobos do cálice $0,3-0,4 \mathrm{~cm}$ compr., eretos, inteiros ou denticulados; corola 3-6 cm compr., tubulosa, subcurvada, vermelha, lobos disjuntos a partir de 3/4 da base, amarelos; tubo de filetes glabro; tubo de anteras ca. $5 \mathrm{~mm}$ compr., cinza azulado.

Comentários: única espécie coletada em ambiente de floresta ombrófila, local úmido, em meio a vegetação arbustiva. É frequente em áreas sombreadas de florestas de altitude do Sudeste do Brasil (BFG 2015). Distingue-se das demais espécies por possuir folhas alternas, pecioladas e com base cordada. Indivíduos férteis são encontrados com muita frequência durante todo o ano. As características diagnósticas utilizadas por Wimmer (1953) para delimitar táxons infraespecíficos variam em um mesmo espécime, portanto optou-se por considerar aqui apenas ao nível específico.

Material examinado: III.1894, fl., E. Ule 210 (R); 13.V.1902, fl., P. Dusen 58 (R); 22.VI.1930, fl., A.C. Brade 10129 (R); 29.V.1935, fl., A.C. Brade (RB 25792); 22.XI.1938, fl., Markgraf 3747 (RB); 25.III.1942, fl., A.C. Brade 17259 (RB); 11.X.1945, fl., A.B. Pereira 20 (RB); 1.IX.1946, fl., A.P. Duarte 237 (RB); 17.VIII.1948, fl., P. Occhioni 1139 (RB); 21.V.1952, fl., A.P. Duarte (RB 79151); 6.III.1962, fl., E. Pereira 7043 (HB); 13.IV.1963, fl., E. Pereira 7561 (HB); 12.IV.1977, fl., G. Martinelli 1612 (RB); 2.V.1985, fl., G. Martinelli 10832 (RB); 10.VI.1993, fl., L. Sylvestre 932 (RB); 26.X.1994, fl., A. Piratininga 96 (RB); 19.V.1999, fl., A. Quinet 221 (RB); 27.VII.1999, fl., C.H.R. de Paula 182 (RB); 15.VI.2004, fl., V.F. Mansano 239 (RB); 17.VII.2004, fl., L. Freitas 915 (RB); 28.X.2011, fl., A. Lobão 1768 (RB); 26.V.2013, fl., I.M. Rollim 04 (RFA); 26.V.2013, fl., I.M. Rollim 05 (RFA); 6.IV.2014, fl., I.M. Rollim 18 (RFA); 6.IV.2014, fl., I.M. Rollim 19 (RFA); 6.IV.2014, fl., I.M. Rollim 20 (RFA); 5.V.2015, fl., I.M. Rollim 27 (RFA); 5.V.2015, fl., I.M. Rollim 28 (RFA); 5.V.2015, fl., I.M. Rollim 29 (RFA).

\section{Siphocampylus umbellatus (Kunth) G. Don}

Fig. 1h

Ervas com 1-3 m de compr., pouco ramificadas, latescentes; ramos tomentosos. Folhas alternas, sésseis; lâmina $12-20 \times 2,5-5 \mathrm{~cm}$, oblonga, ápice agudo, margem denteado-denticulada, base atenuada, membranácea, face adaxial opaca, tricomas raros, face abaxial tomentosa. Flores zigomorfas, isoladas, axilares; pedicelo 15-28 cm compr., não bracteolado; hipanto 4-8 8 10-12 $\mathrm{mm}$, achatado globoso; lobos do cálice 1,2-2,4 cm compr., subulados, inteiros ou denticulados; corola 3,5-4,5 cm compr., subereta, esverdeada, amarelada, tubo da corola menor que os lobos; tubo de filetes piloso; tubo de anteras $1-1,5 \mathrm{~cm}$ compr., cinza.

Comentários: Das espécies do gênero que ocorrem no Itatiaia é a mais diferenciada, com corola pouco vistosa, sem clara distinção entre tubo e lobos. O material examinado acomoda-se bem em S. umbellatus var. umbellatus. Facilmente reconhecida pela corola sem clara distinção entre tubo e lobos e pelo seu látex bastante abundante. A espécie é encontrada em campos de altitude do Sudeste e Sul do Brasil (BFG 2015). Coletada com flores principalmente de junho a outubro.

Material examinado: 26.IV.1995, fl., J.M.A. Braga 2337 (RB); 27.VII.1999, fl., C.H.R. de Paula 183 (RB); 29.VIII.2006, fl., L. Freitas 933 (RB).

\section{Siphocampylus westinianus (Thunb.) Pohl}

Fig. 1i,j

Ervas com 0,4-1,5 $\mathrm{m}$ de compr., ramificadas, latescentes. Folhas verticiladas, 3 ou 4 por verticilo, sésseis ou pecioladas; pecíolo $0,3-1,4 \mathrm{~cm}$ compr.; lâmina $2-7 \times 1,5-3 \mathrm{~cm}$, lanceolada a oval, ápice agudo, margem denteado-denticulada, base arredondada, membranácea, face adaxial glabra, face abaxial com tricomas nas nervuras. Flores zigomorfas, isoladas, axilares; pedicelo $1,5-5 \mathrm{~cm}$ compr., com tricomas esparsos, não bracteolado; hipanto 3-5 × 4-6 mm, obcônico; lobos do cálice $0,3-0,8 \mathrm{~cm}$ compr., estreito-triangulares, margem denticulada; corola $3,5-5,8 \mathrm{~cm}$ compr., tubulosa, subcurvada, vermelha, lobos desiguais com aproximadamente $1 / 4$ do comprimento da corola, base amarelada e ápice verde; tubo de filetes glabro às vezes com tricomas na parte superior; tubo de anteras ca. $5 \mathrm{~mm}$ compr., cinza claro a escuro.

Comentários: Espécie bastante frequente nos campos de altitude e campos rupestres do Sudeste e Centro Oeste do Brasil (BFG 2015). Optou-se aqui por considerar apenas ao nível específico devido a grande dificuldade na delimitação dos táxons infra- 
específicos. Distingue-se de $S$. duploserratus pela coloração dos lobos da corola que são amarelados na base e verdes no ápice, além de apresentar até quatro folhas por verticilo. A margem da folha com dentes quase todos do mesmo tamanho também é útil na distinção desta espécie. Encontrada com flores de janeiro a junho, principalmente nos meses mais quentes.

Material examinado: 23.II.1928, fl., P. Campos Porto 1741 (RB); 31.I.1935, fl., P. Campos Porto 2737 (RB); 28.XI.1938, fl., F. Markgraf 3653 (RB); 26.III.1943, fl., E. Pereira 33B (RB); 8.II.1945, fl., A.C. Brade 17402 (RB); 25.V.1961, fl., E. Pereira 5679 (RB); 6.II.1969, fl., D. Sucre 4663 (RB); 8.V.1975, fl., A.M. Camerik 50 (RB); 17.I.1985, fl., J.F.A. Baumgratz 323 (RB); 10.II.1990, fl., L. Sylvestre 286 (RB); 15.II.1995, fl., J.M.A. Braga 2031 (RB); 13.IV.2008, fl., G. Heiden 989 (RB); 26.V.2013, fl., I.M. Rollim 09 (RFA); 26.V.2013, fl., I.M. Rollim 11 (RFA); 6.V.2014, fl., I.M. Rollim 21 (RFA); 6.V.2014, fl., I.M. Rollim 24 (RFA); s/d. P. Occhioni. (RB 16482).

\section{Wahlenbergia linarioides (Lam.) DC.}

Fig. 1k

Ervas com caule até $50 \mathrm{~cm}$ de compr., latescente, cilíndrico, glabro a pubescente. Folhas opostas, sésseis, as da base espatuladas, as superiores lanceoladas; lâmina $0,1-0,4 \times 0,8-1,7 \mathrm{~cm}$, glabra, ápice agudo a obtuso, margem com dentículos distanciados, base cuneada; inflorescência paniculada, com bráctea séssil $0,1-0,2 \times 0,4-0,8$ $\mathrm{cm}$, lanceolada, glabra, ápice agudo, margem com dentículos distanciados. Flores actinomorfas; pedicelo 1,5-4 cm, glabro; hipanto $0,2-0,4 \times 0,1-0,2$ $\mathrm{cm}$, alongado, obcônico; lobos do cálice $0,2-0,4$ cm compr., ápice agudo, margem inteira; corola 0,2-0,5 cm compr., campanulada, alva ou alborosada, glabra, lobos equivalentes à $2 / 3$ da corola, alva com detalhes em rosa; filetes livres, glabra a esparsamente pilosos; anteras livres, amareladas.

Comentários: Das espécies de Campanulaceae que ocorrem no Itatiaia é a mais distinta e pode ser facilmente reconhecida por sua corola actinomorfa campanulada e estiletes e anteras livres. A espécie é encontrada em campos de altitude do Centro Oeste, Sudeste e Sul do Brasil (BFG 2015). Coletada com flores principalmente de junho a outubro.

Material examinado: 2.XI.1996, fl., J.M.A. Braga 4480 (RB); 22.VIII.2015, fl., A.O. Santiago 29 (RB).

\section{Agradecimentos}

Os autores agradecem à FAPERJ, o apoio financeiro dado ao Projeto Inventários da Flora Fluminense, uma abordagem interdisciplinar (E-26/110.031/2011, E-26/111.392/2012, E-26/111010.001.392/2014 - BIOTA). O primeiro autor agradece à FAPERJ, a bolsa de iniciação científica concedida (E-26/100.912/2013). O segundo autor agradece a Alexander von Humboldt Foundation, à UFRJ (ALV 2013), ao CNPq (proc. 470349/2013-1) e à FAPERJ (E-26/112.476 - INST). Ambos agradecem também aos curadores dos herbários visitados.

\section{Referências}

Angely, J. 1985. Pesquisa e ordenamento histórico, taxonômico, fitogeográfico, estatístico e bibliográfico das lobeliáceas brasileiras. Jornal de Botânica 329: 1-7.

BFG. 2015. Growing knowledge: an overview of Seed Plant diversity in Brazil. Rodriguésia 66: 1085-1113.

Bório, C.B.L. 1968. Relação entre posição sistemática e conteúdo alcalóidico nas lobélias brasileiras: nota prévia. Anais da Sociedade de Botânica do Brasil 19: 171-172.

Braga, R.E. 1956. Lobélias do Brasil - contribuição para o seu estudo. Tribuna Farmacêutica XXXII: $1-8$ e $41-54$.

Cronquist, A. 1981. An integrated system of classification of flowering plants. Columbia University Press, New York. 1626p.

IBAMA. 1994. Plano de ação emergencial para o Parque Nacional do Itatiaia. Brasília. 91p.

Kanitz, A. 1878. Lobeliaceae. In: Martius, C.F.P. von; Eichler, A.W. \& Urban, I. (eds.). Flora Brasiliensis. Lipsae, Munchen. Vol. 6, pars 4, pp. 130-187.

Krochmal, A.,Wilken, L. \& Chten, M. 1970a. Lobeline content of Lobelia inflate: structural environmental and developmental effects. USDA Forest Service Research Paper NE - 178, Upper Darby. 13p.

Montlavo, E.A. 1977. Campanuláceas do município do Rio de Janeiro. Archivos do Jardim Botânico do Rio de Janeiro 20: 5-9.

Wimmer, E.F. 1953. Campanulaceae-Lobelioideae, II. $I n$ : R. Mansfeld (ed.). Das Pflanzenreich. IV-276b, p.i-viii. Akademie-Verlag, Berlin. Pp. 261-814. 